\title{
Oral health, diabetes, and body weight
}

\author{
Luciano Tavares Angelo Cintra, $\mathrm{PhD}^{\mathrm{a}, *}$, Renata Oliveira Samuel, $\mathrm{MSc}^{\mathrm{a}}$, \\ Annelise Katrine Carrara Prieto, MSc ${ }^{\mathrm{a}}$, Dóris Hissako Sumida, PhD ${ }^{\mathrm{b}}$, Eloi Dezan-Júnior ${ }^{\mathrm{a}}$, \\ João Eduardo Gomes-Filho, $\mathrm{PhD}^{\mathrm{a}}$
}

a Department of Endodontics, Araçatuba Dental School, UNESP-Univ Estadual Paulista, Araçatuba, SP, Brazil

${ }^{\mathrm{b}}$ Department of Basic Sciences, Araçatuba Dental School, Univ Estadual Paulista, Araçatuba, SP, Brazil

\section{A R T I C L E I N F O}

\section{Article history:}

Received 13 December 2015

Received in revised form 15 September 2016

Accepted 3 October 2016

\section{Keywords:}

Apical periodontitis

Periodontal disease

Diabetes mellitus

Organ weight

\begin{abstract}
A B S T R A C T
Objectives: The effects of apical periodontitis (AP) and periodontal disease (PD) on organ weights in rats with diabetes mellitus (DM) were evaluated.

Design: Eighty male rats (Rattus norvegicus albinus, Wistar) were divided into eight groups of ten: normoglycemic $(\mathrm{N}), \mathrm{AP}, \mathrm{PD}, \mathrm{AP}+\mathrm{PD}, \mathrm{DM}, \mathrm{DM}+\mathrm{AP}, \mathrm{DM}+\mathrm{PD}$, and $\mathrm{DM}+\mathrm{AP}+\mathrm{PD}$. DM was induced by streptozotocin; AP, by dental exposure to the oral environment; and PD, by periodontal ligature. Blood glucose concentration was measured at $0,6,15$, and 35 days; body weight, measured daily; and animals were sacrificed after 30 days after induction of oral infections. Liver, kidney, pancreas, brain, heart, lungs, and gonads were each weighed. Glycemia, feed intake, organ weight, and body weight were subjected to statistical analyses $(\mathrm{p}<0.05)$.

Results: Glycemic levels were higher in all diabetic groups after day 6, but were consistently similar in normoglycemic groups. Blood glucose was higher in DM + PD and DM + AP + PD groups than in the DM group at days 15 and 35 . The feed intake was similar among all groups. Brain, heart, and gonad weights were significantly increased in DM + AP + PD. Kidney and lung weights were increased in DM, regardless of the presence of oral infections. Liver weight was reduced in AP and/or PD. Pancreas weight was reduced in $\mathrm{DM}$, independent of $\mathrm{AP}$ or $\mathrm{PD}$. Among the normoglycemic groups, there were no significant differences among organ weights.

Conclusion: Apical periodontitis and periodontal disease may potentiate the adverse effects of diabetes.
\end{abstract}

(c) 2016 Published by Elsevier Ltd.

\section{Introduction}

The presence of oral infections has been increasingly associated with systemic and autoimmune diseases (Astolphi et al., 2013; Astolphi et al., 2015; Cintra et al., 2013; Cintra, Samuel, Azuma et al., 2014; Cintra, Samuel, Facundo et al., 2014; Cintra, da Silva Facundo et al., 2014). This relationship exists because of the spread of inflammatory mediators via the bloodstream (Cintra, Samuel, Azuma et al., 2014; Sun, Chen, Zhang, Ren, \& Qin, 2010; Takano et al., 2010). The biological pathways that potentiate autoimmune diseases, such as diabetes mellitus, are the same pathways that potentiate oral infections (Akalin, Işiksal, Baltacioğlu, Renda, \& Karabulut, 2008; Cintra, Samuel, Facundo et al., 2014; Sun et al., 2010; Takano et al., 2010). Thus, increased levels of blood glucose in

\footnotetext{
* Corresponding author at: Department of Endodontics, Araçatuba Dental School, UNESP-Univ Estadual Paulista, R. José Bonifácio, 1193 Araçatuba, São Paulo, Brazil, CEP 16015-050. Fax: +55 1836363253.

E-mail address: lucianocintra@foa.unesp.br (L.T.A. Cintra).
}

diabetics have been associated with apical periodontitis and periodontal disease (Akalin et al., 2008; Cintra, Samuel, Facundo et al., 2014).

The deleterious effects of diabetes mellitus in some organs, such as the liver and kidneys can occur as sequelae to elevated blood glucose levels (Lee et al., 2008). However, to our knowledge, there have been no reports of changes within specific organs that directly resulted from endodontic infections. The liver is an insulin-dependent organ that plays a key role in glucose and lipid homeostasis, and which can be severely affected by diabetes (Seifter \& England, 1982). It participates in the conversion, uptake, oxidation, and metabolism of free fatty acids, phospholipids, and cholesterol synthesis, as well as the secretion of certain classes of plasma lipoproteins (Greenbaum, Gumaa, \& McLean, 1971). Thus, the tighter the glycemic control, the greater the degree of disturbances within the body (Greenbaum et al., 1971).

Organ weight can be a reliable indicator of some physiological changes (Lee et al., 2008). Studies have shown that diabetics tend to have increased kidney weight (Hamadi, Mansour, Hassan, Khalifi-Touhami, \& Badary, 2012; Lee et al., 2008) and decreased 
liver weight. The decrease in liver weight can be attributed to a reduction in the rate of hepatic lipogenesis in diabetics (Greenbaum et al., 1971). The increased weight of the kidneys is due to renal hypertrophy. Some studies have shown that as the kidney does not require insulin for glucose uptake, there is greater accumulation of glycogen (Kumar, Sharmila Banu, \& Murugesan, 2009).

There has been a lack of evidence of changes in the weights of other organs, due to diabetes and concurrent oral infections. Apical periodontitis in particular has been proven to influence the pathogenesis of many diseases (Cintra et al., 2013; Cintra, da Silva Facundo et al., 2014; Cintra, Samuel, Azuma et al., 2014; Cintra, Samuel, Facundo et al., 2014). Thus, with scientific advancement, the development of treatments based on interdisciplinary research has now become indispensable, making a holistic review of the mechanisms of health and disease necessary.

\section{Materials \& methods}

\subsection{Experimental design}

Eighty male rats (Rattus norvegicus albinus, Wistar) with initial mean weight of $250 \mathrm{~g}$ were selected. The animals were housed in temperature-controlled rooms and received water and food ad libitum. The experimental protocol was approved by and conducted in accordance with the guidelines of the institutional ethical committee, and. in accordance with the U.K. Animals (Scientific Procedures) Act, 1986.

\subsection{Induction of diabetes mellitus}

The rats were fasted overnight (14-16 h) and the fasting blood glucose level was measured (day 0 ) from blood samples from the tail vein using an automatic blood glucose monitoring system (Accu-Check ${ }^{\circledR}$ Performa - Roche-Diagnostics Corporation, Indianapolis, IN, USA). The rats were anesthetized with intramuscular administration of ketamine $(87 \mathrm{mg} / \mathrm{kg}$ ) (Francotar - Virbac do Brasil Ind. e Com. Ltda, Roseira, Brasil) and xylazine (13 mg/kg) (Rompum - Bayer S. A., São Paulo, Brazil). They were then randomly assigned to receive an intravenous injection (in the penile vein) of streptozotocin (Sigma-Aldrich Corp., St. Louis, MO, USA) dissolved in citrate buffer solution at $35 \mathrm{mg} / \mathrm{kg}$ for the experimental induction of diabetes (Cintra, Samuel, Azuma et al., 2014; Cintra, da Silva Facundo et al., 2014). For normoglycemic rats, citrate buffer solution $0.01 \mathrm{M}, \mathrm{pH} 4.5$ was administered also in penile vein.

Six days after induction of diabetes, blood samples were collected from each animal to determine glycemic levels (day 6). Only blood glucose levels $>200 \mathrm{mg} / \mathrm{dL}$ were considered in the present study (Cintra et al., 2013; Cintra, da Silva Facundo et al., 2014; Cintra, Samuel, Azuma et al., 2014). Blood glucose concentration was again measured at days 15 and 35 .

\subsection{Induction of oral infections}

After confirmation of hyperglycemia, the animals were sedated for the induction of oral infections. For the development of apical periodontitis, the pulps of the right maxillary first molars were exposed on the mesial surface using surgical round burs (Broca Ln Long Neck - Maillefer, Dentsply Ind. e Com. Ltda, Petrópolis, Rio de Janeiro, Brazil) (Cintra et al., 2013; Cintra, da Silva Facundo et al., 2014; Cintra, Samuel, Azuma et al., 2014).

For the development of periodontal disease, sterile $4 / 0$ silk ligatures (Ethicon, Johnson \& Johnson, São Paulo, SP, Brazil) were placed around the left maxillary second molars (Cintra et al., 2013; Cintra, da Silva Facundo et al., 2014; Cintra, Samuel, Azuma et al.,
2014). After the respective inductions, the following groups were assigned: normoglycemic group $(\mathrm{N}), \mathrm{AP}, \mathrm{PD}, \mathrm{AP}+\mathrm{PD} \mathrm{DM}, \mathrm{DM}+\mathrm{AP}$, $\mathrm{DM}+\mathrm{PD}, \mathrm{DM}+\mathrm{AP}+\mathrm{PD}$.

\subsection{Measurement of feed intake}

Throughout the study, the animals received Labina ${ }^{\circledR}$ food (Purina Agribrands do Brasil Ltda, Paulínia, São Paulo, Brazil) and water ad libitum. The energy content of Labina ${ }^{\circledR}$ was $3.3 \mathrm{Kcal} / \mathrm{g}$ (Table 1). Consumption of food and water was measured every day from the induction of oral infections.

\subsection{Measurement of body weight and organ weight}

Rats were weighed (to the nearest $0.1 \mathrm{~kg}$ ) on a digital balance (model 707; Seca, Hamburg, Germany), at the same time every day for 30 days for the duration of the study.

After 30 days, the animals were sacrificed with an anesthetic overdose of sodium thiopental (Thiopentax; Cristália, Itapira, SP, Brazil). Liver, kidney, brain, heart, lung, and gonads were resected by a trained researcher and weighed on a digital balance (model 707; Seca, Hamburg, Germany). The relative weight of each organ was evaluated according to the index calculated between organ weight (WO) and body weight (BW) of each animal, multiplied by $100(\mathrm{WO} / \mathrm{BW} \times 100)$ (Eleazu, Iroaganachi, Okafor, Ijeh, \& Eleazu, 2013; Kim et al., 2006; Kumar et al., 2009).

\subsection{Statistical analysis}

The total values were tabulated for each experimental group and data were analyzed by a single calibrated operator in a blinded manner. Two-way analysis of variance (ANOVA) followed by the Holm-Sidak method for pairwise multiple comparisons were applied at a significance level of $5 \%(\mathrm{p}<0.05)$.

\section{Results}

\subsection{Blood glucose level}

At day 0 , all rats had similar glycemic levels $(p>0.05)$. In diabetic rats, blood glucose levels were higher than they were in rats without diabetes at days 6,15 , and 30 after induction of DM $(\mathrm{p}<0.05)$. Glycemic levels were similar among all groups without diabetes throughout the duration of the study (Table 2). Among the diabetic rats, the presence of $\mathrm{PD}$ and $\mathrm{PD}+\mathrm{AP}$ increased blood glucose levels on days 15 and 30 , when compared to the DM control. The presence of AP alone also resulted in increased blood glucose levels; however, this difference was not significant $(\mathrm{p}>0.05)$ (Table 2$)$.

\subsection{Feed intake}

Feed intake of diabetic and normoglycemic rats was not significantly different $(p>0.05)$; however, after induction of oral

Table 1

Composition of commercial food fed to rats.

\begin{tabular}{ll}
\hline Component & Amount $(\mathrm{g} / 100 \mathrm{~g})$ \\
\hline Humidity (Max) & 13.0 \\
Crude Protein (Min) & 23.0 \\
Ethereal Extract (Min) & 4.0 \\
Fibrous Matter (Max) & 5.0 \\
Mineral Matter (Max) & 10.0 \\
Calcium (Max) & 1.3 \\
Phosphorus (Min) & 0.85 \\
\hline
\end{tabular}


Table 2

Mean and standard deviations (SD) of blood glucose levels (mg/dL) of rats.

\begin{tabular}{|c|c|c|c|c|c|}
\hline \multirow[t]{2}{*}{ Groups } & \multicolumn{5}{|c|}{ Blood glucose levels $(\mathrm{mg} / \mathrm{dL}) \pm \mathrm{SD}^{*}$} \\
\hline & 0-Day & 6th Day & 15th Day & 35th Day & $\mathrm{n}$ \\
\hline $\mathrm{N}$ & $80.87 \pm 10.90^{\mathrm{a}}$ & $106.75 \pm 013.11^{\mathrm{a}}$ & $114.00 \pm 007.63^{\mathrm{a}}$ & $097.75 \pm 008.06^{\mathrm{a}}$ & 8 \\
\hline $\mathrm{AP}$ & $70.00 \pm 09.24^{\mathrm{a}}$ & $114.25 \pm 018.68^{\mathrm{a}}$ & $116.12 \pm 009.94^{\mathrm{a}}$ & $099.50 \pm 007.50^{a}$ & 8 \\
\hline PD & $74.44 \pm 13.68^{\mathrm{a}}$ & $110.88 \pm 011.39^{a}$ & $111.22 \pm 012.09^{\mathrm{a}}$ & $100.88 \pm 007.70^{\mathrm{a}}$ & 9 \\
\hline $\mathrm{AP}+\mathrm{PD}$ & $71.87 \pm 09.15^{\mathrm{a}}$ & $109.12 \pm 013.20^{\mathrm{a}}$ & $106.00 \pm 004.89^{a}$ & $100.50 \pm 004.78^{a}$ & 8 \\
\hline $\mathrm{D}$ & $75.60 \pm 11.87^{\mathrm{a}}$ & $383.90 \pm 123.54^{\mathrm{b}}$ & $291.70 \pm 142.59^{b}$ & $306.30 \pm 205.30^{\mathrm{b}}$ & 10 \\
\hline $\mathrm{D}+\mathrm{AP}$ & $76.44 \pm 13.25^{\mathrm{a}}$ & $369.33 \pm 088.53^{b}$ & $376.66 \pm 097.70^{\mathrm{bc}}$ & $427.66 \pm 189.42^{\mathrm{bc}}$ & 9 \\
\hline $\mathrm{D}+\mathrm{PD}$ & $77.55 \pm 18.10^{\mathrm{a}}$ & $384.00 \pm 104.37^{\mathrm{b}}$ & $458.88 \pm 099.82^{\mathrm{c}}$ & $531.11 \pm 144.71^{\mathrm{c}}$ & 9 \\
\hline$D+A P+P D$ & $73.40 \pm 07.05^{\mathrm{a}}$ & $395.50 \pm 076.05^{b}$ & $480.60 \pm 988.39^{c}$ & $587.60 \pm 037.48^{c}$ & 10 \\
\hline
\end{tabular}

* Different letters in the same column indicate significant differences $(\mathrm{p}<0.05)$.

infections, consumption decreased in both normoglycemic and diabetic rats, but returned to normal after two days. Thereafter, consumption was similar among all groups throughout the duration of the study $(\mathrm{p}>0.05)$.

\subsection{Body weight}

At day 0, all rats (immediately after administration of streptozotocin) were of similar weight $(p>0.05)$. Within the first 6 days, reductions in body weight were observed among the rats that received streptozotocin; however, this difference was not significant $(p>0.05)$. At day 7 , after the induction of oral infections, reductions in body weight were observed among the groups with AP and/or PD ( $p>0.05)$; nevertheless, by the following day, there was a return to normal values. From day 13 , rats with DM had lower body weights than those without DM and this difference was sustained throughout the study $(\mathrm{p}<0.05)$ (Fig. 1$)$.

From day 13, the presence of AP and/or PD effectively reduced the body weights of both normoglycemic and diabetic rats. However, statistically significant differences were evident only from day 25 and were sustained until day $35(\mathrm{p}<0.05)$. Among the diabetic rats, body weight was reduced to a greater extent in rats with AP + PD than it was in rats with DM only ( $\mathrm{p}<0.05)$, suggesting that the greater the number of oral infetions, the greater the loss in body weight (Fig. 1 ).

From day 6, just after the onset of diabetes was confirmed, rats that had been administered streptozotocin exhibited reductions in body weight, however, this difference was not significant $(p>0.05$ ). Furthermore, from day 13, the presence of AP and/or PD led to reductions in body weight that were sustained until the end of the study, with statistically significant differences from day 25 $(\mathrm{p}<0.05)$. The $\mathrm{DM}+\mathrm{AP}+\mathrm{PD}$ group showed significantly reduced body weight in comparison to the DM group ( $<<0.05$ ) (Fig. 2).

\subsection{Organ weight}

\subsubsection{Liver}

The presence of AP and/or PD in rats effectively reduced the weight of the liver, in comparison to both normoglycemic and diabetic rats without oral infections $(p<0.05)$. The presence of isolated DM had no significant effect on liver weight $(\mathrm{p}>0.05)$ (Graph 1).

\subsubsection{Kidney}

The weight of the kidney of diabetic rats was significantly increased in comparison to that of normoglycemic rats regardless of the presence of AP or PD $(\mathrm{p}<0.05)$. The presence of AP and/or PD did not significantly affect the weight of the kidneys $(p>0.05)$ (Graph 1).

\subsubsection{Pancreas}

The weight of the pancreas was significantly reduced in diabetic rats in comparison to normoglycemic rats, regardless of the presence AP or PD $(\mathrm{p}<0.05)($ Graph 1$)$.

\subsubsection{Brain}

The weight of the brain was greater in diabetic rats, compared to normoglycemic rats; however, this increase was statistically significant only in the presence of oral infections. Brain weights were significantly higher in the $\mathrm{DM}+\mathrm{PD}$ and $\mathrm{DM}+\mathrm{AP}+\mathrm{PD}$ groups than they were in the normoglycemic groups with the respective infections $(\mathrm{p}<0.05)($ Graph 1$)$.

\subsubsection{Heart}

The trend in the weight of the heart was similar to that of the brain. An increase was observed in the heart weights of diabetic rats compared to that of normoglycemic rats. However, this

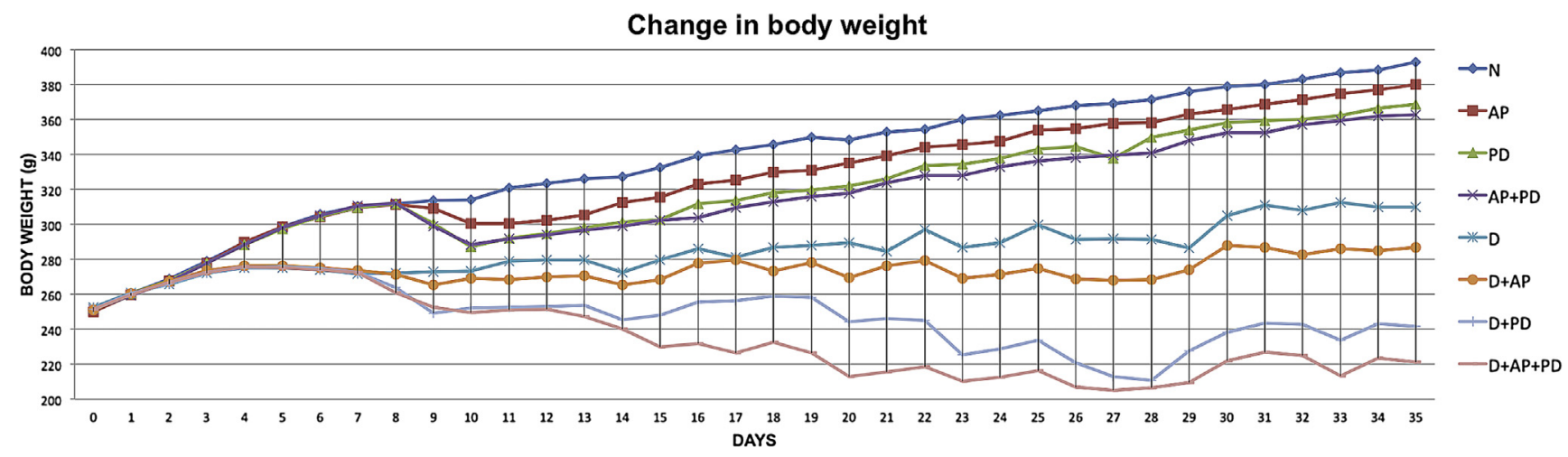

Fig. 1. Changes in body weight of normoglycemic and diabetic rats.

$\mathrm{N}$, normoglycemic rats; AP, apical periodontitis; $\mathrm{PD}$, periodontal disease; $\mathrm{DM}$, diabetes mellitus 


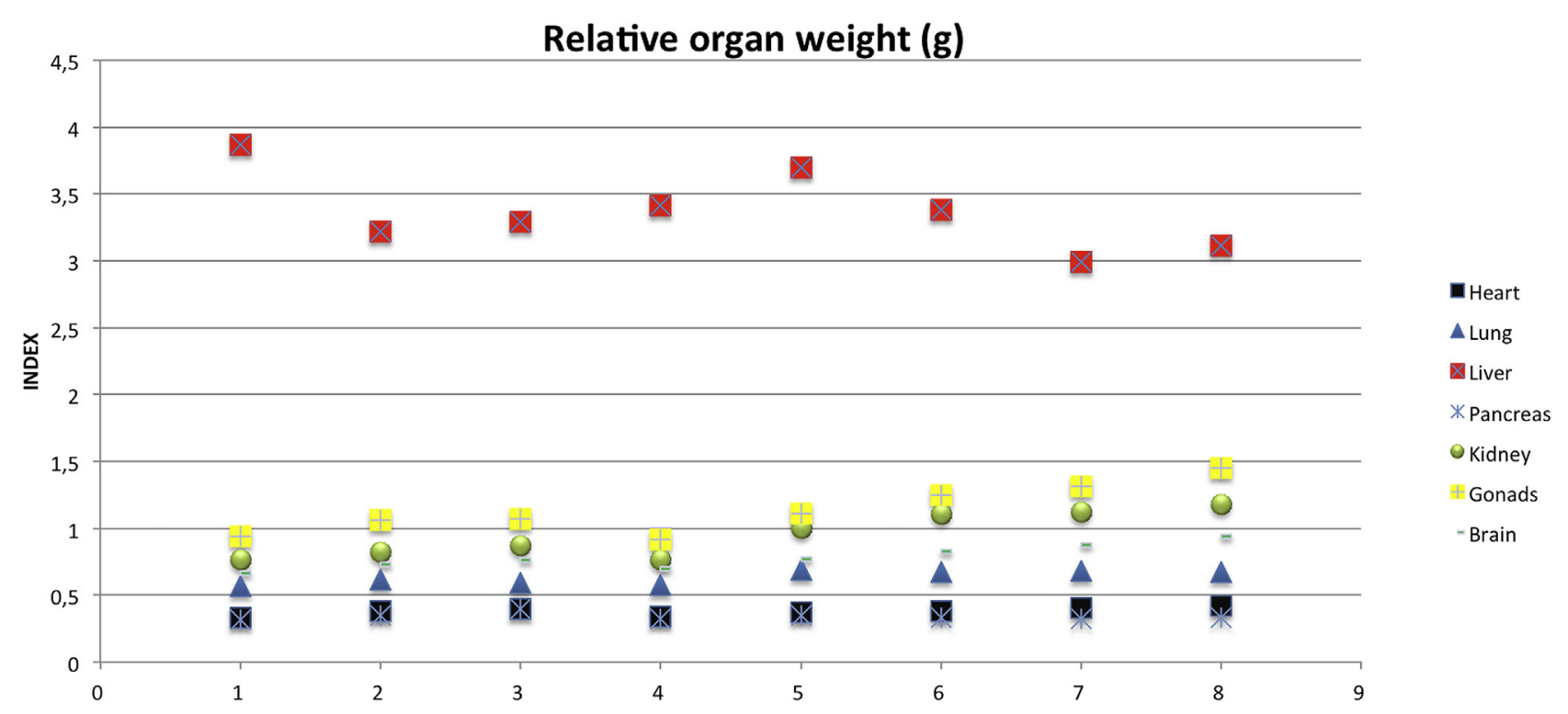

Fig. 2. Relative organ weight index of normoglycemic and diabetic rats.

$\mathrm{N}$, normoglycemic rats; AP, apical periodontitis; PD, periodontal disease; DM, diabetes mellitus

increase was statistically significant only in the presence of concomitant oral infections. The heart weights in the DM + AP + PD group were comparatively greater than those of the AP + PD group $(\mathrm{p}<0.05)($ Graph 1).

\subsubsection{Lung}

The lung weights were significantly greater in diabetic rats regardless of the presence of AP and/or PD $(\mathrm{p}<0.05)$. Neither endodontic nor periodontal infections exerted any significant effects on lung weights (Graph 1).

\subsubsection{Gonads}

The weight of the gonads was also greater in diabetic animals than it was in normoglycemic animals; however, this difference was statistically significant only between the DM+PD and $\mathrm{DM}+\mathrm{AP}+\mathrm{PD}$ groups, in comparison to the respective normoglycemic groups $(\mathrm{p}<0.05)($ Graph 1$)$.

\section{Discussion}

The present study evaluated whether the presence of oral infections affects systemic health through changes in the organ weights and blood glucose levels of Wistar rats. The presence of the periapical lesions and the periodontal diseases were confirmed radiographically. We inferred from our results, that the presence of two focal oral infections of diabetics, led to alterations in the weights of some organs, such as the liver, brain, heart, and gonads. These results are consistent with those of other studies that demonstrate systemic alterations in lipid profile (Cintra et al., 2013), glycated hemoglobin (Cintra, Samuel, Facundo et al., 2014), blood count (Cintra, da Silva Facundo et al., 2014), and inflammatory mediators (Cintra, Samuel, Azuma et al., 2014) with similar concurrent infections (AP and PD) in similar animal models. The presence of AP and PD, either in isolation or in association with diabetes or normoglycemic, led to significant reductions in the weight of the liver. This finding shows that the presence of AP, PD, or both can have deleterious effects on the liver.

The liver is an insulin dependent organ that plays a pivotal role in glucose and lipid homeostasis, and which can be severely affected by diabetes (Gupta, Raju, Prakash, \& Baquer, 1999).
Reductions in the liver weight of diabetics possibly occur because of decreased hepatic lipogenesis and increased lipolysis (Gupta et al., 1999). There are defective responses to insulin signals in diabetics; thus, because the liver is insulin-dependent, glucose is not efficiently utilized. Consequently, there is an increase in the concentration of glucose in the liver that leads to other non-insulin dependent structures, such as the kidneys, nerves, and brain (Baquer, Gupta, \& Raju, 1998). Based on our results, both endodontic and periodontal infections exacerbated the effects of diabetes, as evidenced by reductions in liver weight. These findings are consistent with those of other studies that have demonstrated that the presence of oral infections increases levels of blood lipids in diabetic rats (Cintra et al., 2013) and increases insulin resistance (Astolphi et al., 2013, 2015).

In addition to the changes observed in organ weights, an increase in the concentration of serum glucose was also observed in rats with $\mathrm{AP}+\mathrm{PD}$ at days 15 and 35 . These findings confirm the hypothesis that these oral infections potentiate the pathogenesis of diabetes mellitus, and are consistent with those of another study (Cintra, Samuel, Facundo et al., 2014). The significant increases in the weights of the brain, heart, and gonads in $\mathrm{DM}+\mathrm{AP}+\mathrm{PD}$ rats were possibly due to increased blood glucose levels in the presence of oral infections. Excess glucose in non-insulin dependent organs may lead to increased organ weight due to increased lipogenesis, protein and glycogen synthesis and the over-utilization of glucose (Meyer et al., 1998). These changes may lead to serious microvascular renal complications, which result in metabolic changes in the pathogenesis of diabetic nephropathy (Luder \& Sheldon, 1955). Despite the increases observed in the organ weights of diabetic rats, no relationship with feed intake (which remained constant throughout the investigation) was evident among the groups.

An increase in kidney and lung weights in the presence of oral infections was evident; however, this difference was not significant. In other studies, significant effects of periodontal disease on kidney homeostasis were reported (Sharma et al., 2014; Siribamrungwong, Yothasamutr, \& Puangpanngam, 2013; Tadakamadla, Kumar, \& Mamatha, 2014). Our results may have been different because of differences in methodology. The present study was conducted in animals with lesions of a standard size, on a single 
tooth. Other comparable studies were conducted in humans with periodontal disease on multiple teeth concurrently and generally with lesions of various sizes. The animal model has the advantage of being able to simulate the pathogenesis of several diseases with greater control of variables (Clause, 1993). The use of streptozotocin to induce the diabetic state in rats via its toxicity to the pancreatic beta cells has also been widely accepted and shows similar results with genetically altered diabetic rat or studies in humans especially with regard to systemic effects of oral infections (Elburki et al., 2016; Samuel, Gomes Filho, Dezan-Junior, \& Cintra, 2014; Suzuki et al., 2016). In this model, reduced pancreatic weight is generally observed in rats that have been administered streptozotocin, as compared to normoglycemic rats (Shimizu, Shiratori, Hayashi, Fujiwara, \& Horikoshi, 2000), which is consistent with the results of the present study.

Regarding body weight, there was an expected and significant weight loss in diabetic rats. The presence of oral infections in diabetic rats also led to reduced body weight. Weight loss in diabetics could be attributed to a lack of insulin, which causes increased glycolysis and decreased synthesis of sugars and proteins (Frayn, 1981). Moreover, studies show that the presence of both apical periodontitis (Astolphi et al., 2013, 2015) and periodontal disease influences insulin resistance (Lim et al., 2014). Thus, our results are in agreement with our hypothesis: the greater the degree of insulin resistance owing to the presence of oral infections, the lower the rate of glycolysis and consequently, the lower the body weight due to a reduction in the synthesis of proteins and sugars.

The results of the present study clearly demonstrate the relationship between infections of dental origin and systemic health, as evidenced by increased blood glucose levels and alterations in organ weights. Although this relationship has been studied in infectious periodontal disease (Sun et al., 2010; Takano et al., 2010), we demonstrated that infections of endodontic origin also yield similar results. These analyses are key to shifting paradigms that suggest that endodontic infections are limited to the oral cavity and are simply cases of transient bacteremia. Interdisciplinary research should increasingly become the standard in both the dental and medical fields. Further studies are necessary to understand better the mechanisms underlying the relationships between oral infections and systemic disease.

\section{Conclusion}

The presence of oral infections exacerbates the deleterious effects of diabetes mellitus, by effectively increasing blood glucose levels and altering the weights of the liver, brain, heart, and gonads.

\section{Conflict of interest}

None.

\section{Ethical approval}

Approved by Animal Ethical Committee of the College of Dentistry Araçatuba, São Paulo State University [00538-2012].

\section{Acknowledgement}

This work was supported by São Paulo State Research Foundation (FAPESP) [Grant No. 2012/02083-8].

\section{References}

Akalin, F. A., Ișiksal, E., Baltacioğlu, E., Renda, N., \& Karabulut, E. (2008). Superoxide dismutase activity in gingiva in type-2 diabetes mellitus patients with chronic periodontitis. Archives of Oral Biology, 53(1), 44-52.

Astolphi, R. D., Curbete, M. M., Colombo, N. H., Shirakashi, D. J., Chiba, F. Y., Prieto, A. K., et al. (2013). Periapical lesions decrease insulin signal and cause insulin resistance. Journal of Endodontics, 39(5), 648-652.

Astolphi, R. D., Curbete, M. M., Chiba, F. Y., Cintra, L. T., Ervolino, E., da Mota, M. S., et al. (2015). Periapical lesions decrease insulin signaling in rat skeletal muscle. Journal of Endodontics, 41(8), 1305-1310.

Baquer, N. Z., Gupta, D., \& Raju, J. (1998). Regulation of metabolic pathways in liver and kidney during experimental diabetes: effects of antidiabetic compounds. Indian Journal of Clinical Biochemistry, 13(2), 63-80.

Cintra, L. T., da Silva Facundo, A. C., Azuma, M. M., Sumida, D. H., Astolphi, R. D., Bomfim, S. R., et al. (2013). Pulpal and periodontal diseases increase triglyceride levels in diabetic rats. Clinical Oral Investigations, 17(6), 1595-1599.

Cintra, L. T., Samuel, R. O., Azuma, M. M., Ribeiro, C. P., Narciso, L. G., de Lima, V. M., et al. (2014). Apical periodontitis and periodontal disease increase serum IL-17 levels in normoglycemic and diabetic rats. Clinical Oral Investigations, 18(9), 2123-2128.

Cintra, L. T., Samuel, R. O., Facundo, A. C., Prieto, A. K., Sumida, D. H., Bomfim, S. R., et al. (2014). Relationships between oral infections and blood glucose concentrations or HbA1c levels in normal and diabetic rats. International Endodontic Journal, 47(3), 228-237.

Cintra, L. T., da Silva Facundo, A. C., Prieto, A. K., Sumida, D. H., Narciso, L. G., Mogami Bomfim, S. R., et al. (2014). Blood profile and histology in oral infections associated with diabetes. Journal of Endodontics, 40(8), 1139-1144.

Clause, B. T. (1993). The Wistar rat as a right choice: Establishing mammalian standards and the ideal of a standardized mammal. Journal of the History of Biology, 26, 329-349.

Elburki, M. S., Moore, D. D., Terezakis, N. G., Zhang, Y., Lee, H. M., Johnson, F., et al. (2016). A novel chemically modified curcumin reduces inflammation-mediated connective tissue breakdown in a rat model of diabetes: Periodontal and systemic effects. Journal of Periodontal Research. http://dx.doi.org/10.1111/ jre.12381 [Epub ahead of print].

Eleazu, C. O., Iroaganachi, M., Okafor, P. N., Ijeh, I. I., \& Eleazu, K. C. (2013). Ameliorative potentials of ginger (Z. officinale roscoe) on relative organ weights in streptozotocin induced diabetic rats. International Journal of Biomedical Science, 9(2), 82-90.

Frayn, K. N. (1981). Effects of diabetes and of injury on muscle protein in the mouse and their interaction. Diabetologia, 20(2), 139-144.

Greenbaum, A. L., Gumaa, K. A., \& McLean, P. (1971). The distribution of hepatic metabolises and the control of the pathways of carbohydrate metabolism in animals of different dietary and hormonal status. Archives of Biochemistry and Biophysics, 143, 617-663.

Gupta, D., Raju, J., Prakash, J., \& Baquer, N. Z. (1999). Change in the lipid profile, lipogenic and related enzymes in the livers of experimental diabetic rats: Effect of insulin and vanadate. Diabetes Research and Clinical Practice, 46(1), 1-7.

Hamadi, N., Mansour, A., Hassan, M. H., Khalifi-Touhami, F., \& Badary, O. (2012). Ameliorative effects of resveratrol on liver injury in streptozotocin-induced diabetic rats. Journal of Biochemical and Molecular Toxicology, 26(10), 384-392.

Kim, J. D., Kang, S. M., Seo, B. I., Choi, H. Y., Choi, H. S., \& Ku, S. K. (2006). Anti-diabetic activity of SMK001, a poly herbal formula in streptozotocin induced diabetic rats: Therapeutic study, Biological and Pharmaceutical Bulletin, 29(3), 477-482.

Kumar, G., Sharmila Banu, G., \& Murugesan, A. G. (2009). Attenuation of Helicteres isora L. bark extracts on streptozotocin-induced alterations in glycogen and carbohydrate metabolism in albino rats. Human and Experimental Toxicology, 28 (11), 689-696.

Lee, S. I., Kim, J. S., Oh, S. H., Park, K. Y., Lee, H. G., \& Kim, S. D. (2008). Antihyperglycemic effect of Fomitopsis pinicola extracts in streptozotocininduced diabetic rats. Journal of Medicinal Food, 11(3), 518-524.

Lim, S. G., Han, K., Kim, H. A., Pyo, S. W., Cho, Y. S., Kim, K. S., et al. (2014). Association between insulin resistance and periodontitis in Korean adults. Journal of Clinical Periodontology, 41(2), 121-130.

Luder, J., \& Sheldon, W. (1955). A familial tubular absorption defect of glucose and amino acids. Archives of Disease in Childhood, 30(150), 160-164.

Meyer, C., Stumvoll, M., Nadkarni, V., Dostou, J., Mitrakou, A., \& Gerich, J. (1998). Abnormal renal and hepatic glucose metabolism in type 2 diabetes mellitus. Journal of Clinical Investigation, 102(3), 619-624.

Samuel, R. O., Gomes Filho, J. E., Dezan-Junior, E., \& Cintra, L. T. A. (2014). Streptozotocin-Induced rodent models of diabetes: Protocol comparisons. In E. L. Gauthier (Ed.), New York: Nova Science Publishers.

Seifter, S., \& England, S. (1982). The Liver: Biology and pathobiology energy metabolism. Energy Metabolism, 21, 9-49 In: Arias, I., Popper, H., Schacter, D. (Eds.).

Sharma, P., Dietrich, T., Sidhu, A., Vithlani, V., Rahman, M., Stringer, S., et al. (2014). The periodontal health component of the renal impairment In secondary care (RIISC) cohort study: A description of the rationale, methodology and initial baseline results. Journal of Clinical Periodontology(April 16).

Shimizu, K., Shiratori, K., Hayashi, N., Fujiwara, T., \& Horikoshi, H. (2000). Effect of troglitazone on exocrine pancreas in rats with streptozotocin-induced diabetes mellitus. Pancreas, 21(4), 421-426. 
Siribamrungwong, M., Yothasamutr, K., \& Puangpanngam, K. (2013). Periodontal treatment reduces chronic systemic inflammation in peritoneal dialysis patients. Therapeutic Apheresis and Dialysis [Epub ahead of print].

Sun, W. L., Chen, L. L., Zhang, S. Z., Ren, Y. Z., \& Qin, G. M. (2010). Changes of adiponectin and inflammatory cytokines after periodontal intervention in type 2 diabetes patients with periodontitis. Archives of Oral Biology, 55(12), 970-974.

Suzuki, Y., Nakamura, N., Miyabe, M., Nishikawa, T., Miyajima, S., Adachi, K., et al. (2016). Anti-inflammatory role of glucose-dependent insulinotropic

polypeptide in periodontitis. Journal of Diabetes Investigation, 7(4), 497-505.
Tadakamadla, J., Kumar, S., \& Mamatha, G. P. (2014). Comparative evaluation of oral health status of chronic kidney disease (CKD) patients in various stages and healthy controls. Special Care in Dentistry, 34(3), 122-126.

Takano, M., Nishihara, R., Sugano, N., Matsumoto, K., Yamada, Y., Takane, M., et al. (2010). The effect of systemic anti-tumor necrosis factor-alpha treatment on Porphyromonas gingivalis infection in type 2 diabetic mice. Archives of Oral Biology, 55(5), 379-384. 